\title{
BMJ Open Comparative effectiveness and safety of erythropoiesis-stimulating agents (biosimilars vs originators) in clinical practice: a population-based cohort study in Italy
}

\author{
Francesco Trotta, ${ }^{1}$ Valeria Belleudi, ${ }^{1}$ Danilo Fusco, ${ }^{1}$ Laura Amato, ${ }^{1}$ \\ Alessandra Mecozzi, ${ }^{2}$ Flavia Mayer, ${ }^{1}$ Massimo Sansone, ${ }^{2}$ Marina Davoli, ${ }^{1}$ \\ Antonio Addis ${ }^{1}$
}

To cite: Trotta F, Belleudi V, Fusco D, et al. Comparative effectiveness and safety of erythropoiesis-stimulating agents (biosimilars vs originators) in clinical practice: a population-based cohort study in Italy. BMJ Open 2017;7:e011637. doi:10.1136/bmjopen-2016011637

- Prepublication history and additional material is available. To view please visit the journal (http://dx.doi.org/ 10.1136/bmjopen-2016011637).

$\mathrm{MD}$ and $\mathrm{AA}$ equally shared the oversight of this work.

Received 22 February 2016 Revised 23 December 2016 Accepted 23 January 2017

CrossMark

\begin{abstract}
${ }^{1}$ Department of Epidemiology, Lazio Regional Health Service, Rome, Italy ${ }^{2}$ Drug Policy Area, General Directorate for Health, The Lazio Region, Rome, Italy
\end{abstract}

Correspondence to Dr Francesco Trotta; f.trotta@deplazio.it

\section{ABSTRACT}

Objectives: To evaluate the benefit/risk profile of epoetin $\alpha$ biosimilar with the erythropoiesis-stimulating agents (ESAs) originators when administered to naive patients from clinical practice.

Design: Population-based observational cohort study. Setting: All residents in the Lazio Region, Italy, with chronic kidney disease (CKD) or cancer retrieved from the Electronic Therapeutic Plan (ETP) Register for ESA between 2012 and 2014.

Participants: Overall, 13470 incident ESA users were available for the analysis, 8161 in the CKD and 5309 in the oncology setting, respectively.

Interventions: ESAs identified through the ATC B03XA were divided into 3 groups: (1) biosimilars; (2) epoetin $\alpha$ originator and (3) other originators. Patients were exposed to ESAs from the date of activation of the ETP, until the end of a 6-month follow-up period.

Outcome measures: Effectiveness (all-cause mortality and blood transfusion) and safety (major cardiovascular events, blood dyscrasia). A composite outcome including all-cause mortality, blood transfusion and major cardiovascular events was predefined. HRs of any outcome were estimated through Cox regression.

Results: We found no differences between patients on biosimilars or all originators with regard to the risk estimates of all-cause mortality, blood transfusion, major cardiovascular events and blood dyscrasia in the CKD setting. The composite outcome confirmed these results (biosimilars vs epoetin $\alpha$ originators: adjusted $\mathrm{HR}=1.02,95 \% \mathrm{Cl} 0.78$ to 1.33 ; biosimilars vs other originators: adjusted $\mathrm{HR}=1.09,95 \% \mathrm{Cl} 0.85$ to 1.41 ). Comparable risk estimates were observed between biosimilars and all originators in the oncology setting. Conclusions: In both settings, our findings are suggestive of no difference between biosimilars and originators on relevant effectiveness and safety outcomes. This study may contribute to settling future drug policy for the health services and provides reassurance on the approval pathway for biosimilars.

\section{Strengths and limitations of this study}

- The Electronic Therapeutic Plan Register was set up for the clinical purpose of ensuring a higher appropriateness of erythropoiesis-stimulating agents (ESAs) use as well as a very low misclassification of diagnosis and incident users.

- Many potential confounders identified through multiple database linkage were considered to allow high completeness of data.

- The robustness of risk estimates was investigated through two statistical approaches, that is, multivariate regression and genetic matching, as well as evaluating multiple outcomes.

- It was not possible to control risk estimates for confounding factors such as iron supplementation, smoking status, body mass index, socioeconomic status as well as ESAs dose/posology.

- Relevant information for the oncology setting (eg, tumour type, stage, chemotherapy) was not available and this contributed to the unmeasured residual confounding.

The oncology setting merits further research, taking into account tumour types, tumour stage and anticancer chemotherapy administered.

\section{INTRODUCTION}

The erythropoiesis-stimulating agents (ESAs) play a major role in the management of anaemia in the nephrology and oncology settings. The benefits of treatment with ESAs are well documented, and national and international guidelines recommend them. ${ }^{1-6}$

ESAs consume a significant amount of the healthcare budget and their high costs may represent a barrier to wider access to ESA 
therapy. ${ }^{7}$ A survey on anaemia management in developed countries has shown significant gaps in achieving recommended therapeutic targets. ${ }^{8}$ The problem might be even worse in developing countries.

With the patents expiration for $\alpha$ and $\beta$ epoetins in 2004, biosimilar epoetins may result in a wider access for patients to such therapy. The first biosimilar of epoetin $\alpha$ has been authorised in the European Union (EU) since 2007. ${ }^{9}$ A specific approval pathway exists in the EU for biosimilars aiming at demonstrating similarity to the originator in terms of quality characteristics, biological activity, safety and efficacy based on a comprehensive comparability exercise. ${ }^{10}$ However, the acceptance of biosimilars in the medical community continues to be limited despite they represent a key element for the sustainability of the National Health Service (NHS). ${ }^{11} 12$ Italian usage data demonstrate that in 2014 biosimilars represented $21.1 \%$ of the consumption (as defined daily doses (DDD)/1000 inhabitants die) of the entire ESAs. ${ }^{13}$ The extent of the ESAs biosimilar use deeply varies among Italian regions, where different policies have been implemented. ${ }^{14}$

The main barriers for the biosimilar diffusion are the lack of comparative effectiveness and safety data between different ESAs (including both originators and biosimilars) when used in current clinical practice for the treatment of chemotherapy-induced anaemia or chronic kidney disease (CKD) as well as the lack of clinical efficacy data of switching strategies.

A network meta-analysis of randomised controlled trial (RCT) data published in 2014 comparing the efficacy and safety of ESAs (all originators and biosimilars were included) in adult patients with CKD gave inconclusive results due to the poor quality of the available evidence, thus highlighting the need for direct comparative studies. ${ }^{15}$

In the oncology setting, the hesitancy of clinicians to prescribe biosimilar ESAs is even stronger since the regulatory approval has been made via data extrapolation. There is concern on the extrapolation of the results obtained in renal anaemia to other therapeutic indications of the reference product. ${ }^{16}$ However, the accumulating evidence from current practice on biosimilar ESA usage in oncology is reassuring, although based on small studies. ${ }^{17-19}$

A further debated issue on ESA biosimilars concerns the switching strategies from originator to biosimilar in real practice. A recent study suggests that switching is not associated with a change in outcomes. ${ }^{20}$ Moreover, a usage study conducted in Italy demonstrated that $17 \%$ of patients switched between different ESAs over a 1-year treatment period, and interestingly the phenomenon was largest towards originators than biosimilars. ${ }^{14}$

Finally, it should be acknowledged that safety concerns reported in the European risk management plans of ESAs included thromboembolic events, pure red cell aplasia as well as tumour growth potential which also merit evaluation in the general population. ${ }^{921}$
It appears clear that the relative effectiveness and safety of ESAs used in current clinical practice is an open clinical question to be investigated through a large, aetiological study using hard end points. Real-world experience is thus useful either in the case of naïve patients.

\section{OBJECTIVES}

The primary objective was to evaluate the comparative effectiveness and safety of biosimilars and originators of ESAs in naive patients. The secondary objective was to investigate factors influencing the probability of receiving an ESA biosimilar or an originator (ie, the determinants of use).

\section{Study design and source of data}

An observational, record-linkage cohort study was carried out in a large Italian region (Lazio), where the resident population counts around six million inhabitants.

The study cohort was enrolled using the Electronic Therapeutic Plan Register (ETPR) which collects information on ESA prescriptions reimbursed and dispensed by the regional health service. This register has to be filled in by specialists for each single patient treated with ESA.

The ETPR collects information on: patient's demographic characteristics (age, sex), clinical data (diagnosis, setting and indication for ESA use, haemoglobin (Hb) level at baseline, use of special nutrition for CKD), ESAs information (drug trade name, number of dispensed packages) and therapy regimen (date of activation of the ETP and duration of the ETP in months). The ETPR also includes a section where specialists should declare whether it is a first prescription of ESA for each patient.

Patients in the ETPR can be linked individually and anonymously to regional health information systems: Health Care Assistance File (HCAF), Mortality Information System (MIS), Hospital Information System (HIS).

The HCAF contains demographic and residence information at a specific date, life status and date of death, referring to all residents registered in the regional health service.

The MIS includes the date, the place and the cause of death (according to the International Classification of Diseases, ninth revision (ICD-9) for all patients resident in the Lazio Region.

The HIS collects information on all hospital discharges registered in a regional hospital, in particular: dates of admission and discharge, diagnoses and procedures according to the ICD-9, Clinical Modifications (both as primary and secondary). Data from day hospital/day surgery were included and considered as hospitalisation.

For HCAF and HIS, the routinely collected data are available monthly, while the data registered in the other information systems are accessible yearly. 


\section{Population}

We selected from ETPR all ESA prescriptions registered from 1 January 2012 to 31 December 2014. We restricted the cohort to incident ESAs users (ie, a proxy of naive patients) defined as those participants who start for the first time an ETP for ESA in the study period (information declared by the specialist). Only patients in CKD and oncology settings were included. Patients who change ESA products within the same ETP or with two different ETPs active in the same period were excluded.

\section{Exposure to study drugs}

The study drugs concern all ESAs available in the region during the study period identified through the ATC B03XA. In particular, we considered the following substances: (1) epoetin $\alpha$ (Eprex; Abseamed, Binocrit); (2) epoetin zeta (Retacrit); (3) epoetin $\beta$ (Neorecormon); (4) epoetin theta (Eporatio); (5) darbepoetin $\alpha$ (Aranesp); (6) methoxypolyethyleneglycol-epoetin $\beta$ (Mircera).We defined as biosimilars Abseamed, Binocrit and Retacrit having demonstrated biosimilarity versus Eprex, while the others were originators.

For each setting (ie, CKD and oncology), biosimilars were compared, both with the originator of epoetin $\alpha$ (Eprex) or other originators (Neorecormon, Eporatio, Aranesp, Mircera). We used the DDD to determine mean ESA consumption (DDD of each ETP were calculated from the number of packages of ESA products dispensed over the ETP duration).

We considered patients exposed to ESAs from the date of activation of the ETP, corresponding to the dispensation of the ESA medicinal product (ie, the index date), until the end of the follow-up period, without considering interruption or change of the treatment (intentionto-treat approach).

\section{Outcomes}

The outcomes considered, retrieved from health information systems, were the following: (1) all-cause mortality; (2) need for blood transfusion; (3) major cardiovascular events (MACE), defined as acute myocardial infarction (AMI) or stroke or thrombosis, whichever came first; (4) blood dyscrasia (haemolytic anaemia or aplastic anaemia or 'other and unspecified anaemia', whichever came first); and (5) hypersensitivity reactions. The use of a comprehensive composite outcome (all-cause mortality or AMI or stroke or thrombosis or blood transfusion, whichever came first) was preplanned. Online supplementary table $\mathrm{S} 1$ gives details about outcome definitions.

\section{Follow-up}

All patients were followed up from the index date until death, effectiveness or safety event or end of the 6 months from the index date, whichever came first.

\section{Potential confounders}

We took five main categories of potential confounders into account: demographic characteristics of the participants, baseline Hb levels $(<8$; 8 to $<10$; 10 to $<11$; $\geq 11$ ), history of selected comorbidities retrieved from HIS in the 2 years before the index date and presence of diabetes detected according to a previously established method, ${ }^{22}$ healthcare use (defined as number of previous hospitalisations) and ESAs therapy regimen. Online supplementary table S2 gives details on the specific confounders included in the study. No data were available on alcohol use, smoking status, body mass index, over the counter drugs, and iron or vitamin supplementation.

\section{Statistical analysis}

We reported patients' characteristics by ESAs exposure status in each clinical setting (ie, CKD and oncology); ESAs were divided into three groups: (1) biosimilars; (2) epoetin $\alpha$ originator and (3) other originators. We compared characteristic distribution of patients on biosimilars with those on originators (ie, epoetin $\alpha$ biosimilars vs epoetin $\alpha$ originator; epoetin $\alpha$ biosimilars vs other originators) by using a t-test for continuous variables and a $\chi^{2}$ test for categorical ones.

In each clinical setting, to compare the effect of biosimilars with the originators on each outcome, we used Cox proportional hazard models in order to estimate crude and adjusted HRs, with 95\% CIs. For the risk adjustment, among all the patient characteristics potentially associated with each outcome, we considered those selected by a stepwise procedure (significance for input 0.10 and removal 0.05 ); details of the statistical model were also reported.

To test the robustness of results, we performed a sensitivity analysis using the genetic matching, a statistical matching technique that attempts to reduce the bias due to confounding maximising the covariate balance between the treatments in study. ${ }^{23}$ For each setting, we performed two different genetic matches: (1) patients with biosimilars versus patients with originator $\alpha$, (2) patients with biosimilars versus patients with other originator. For each pair matched, we estimated the treatment effect for five primary outcomes and compared it with that obtained in the main analysis.

Cumulative probabilities of receiving a blood transfusion and survival curves by ESA exposure status were estimated through the Cox model in order to assess the time relationship of the effect on such outcomes of biosimilars as compared with epoetin $\alpha$ or other originators.

As secondary objective, we investigated the factors influencing the prescription of biosimilars or originators through a logistic regression model estimating the OR for baseline characteristics and the related 95\% CI. Among all factors potentially associated with the probability of receiving an ESA biosimilar or an originator, age, gender, Hb levels and number of previous hospitalisations were considered as an a priori determinant of use; the others were selected by a stepwise procedure (significance for input 0.10 and removal 0.05 ). 
All statistical analyses were performed using SAS software (V.9.2) and R software (V.3.2.2).

\section{Patient involvement}

No patients were involved in setting the research question or the outcome measures; nor were they involved in recruitment or the design and implementation of the study. However, the study originated from the activities conducted by the working group on biosimilars appointed by the Lazio Region with the task of informing regional policy on biosimilars and promoting their appropriate use. The working group on biosimilars includes clinicians, prescribers, methodologists and decision-makers who shared protocol methods, research questions and findings. We identified no predefined hypothesis and no formal estimate of the sample size was performed. There is a plan regarding the involvement of prescribers in the dissemination of results.

\section{RESULTS}

Overall, 43707 ETPs for ESAs prescribed to 21955 patients were available during the study period in the Lazio Region; 14404 patients were reported to be incident users of ESAs (ie, naive patients). Applying the exclusion criteria, a sample of 13470 incident users of ESAs was available for the analysis, 8161 in the nephrology setting and 5309 in the oncology setting, respectively (figure 1). The use of biosimilars in naive patients is residual accounting for the 1.9\% (154 out of 8161) and 8.5\% (453 out of 5309 ) in the two settings. Baseline characteristics of patients enrolled are presented in table 1.

\section{Baseline characteristics (CKD and oncology)}

Patients exposed to biosimilars and originators can be considered comparable overall for baseline characteristics in both settings, although some specific differences exist and are further described.

Specifically, in the CKD setting, patients receiving biosimilars have higher $\mathrm{Hb}$ levels (ie, $\geq 10 \mathrm{~g} / \mathrm{dL}$ ), were less

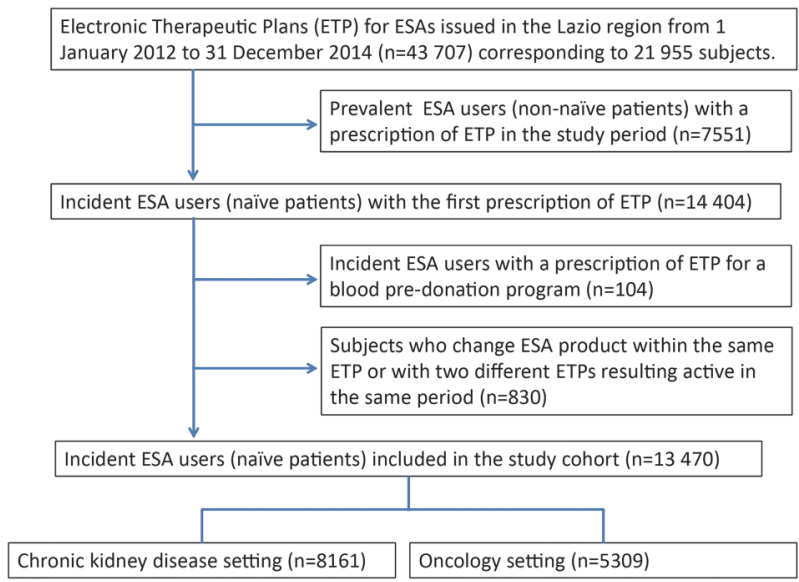

Figure 1 Flow chart of patients included in the study cohort. ESA, erythropoiesis-stimulating agent. hypertensive and less hospitalised than those on epoetin $\alpha$ originator. When compared with other originators, biosimilar users presented more frequently with serious heart diseases (AMI, arrhythmia, heart failure).

In oncology, among patients receiving biosimilars, there were more men (51.4\%) compared with those receiving other originators $(43.5 \%)$; gender did not differ when biosimilars were compared with epoetin $\alpha$ originator.

Although statistical significance is reached, duration of the ETP and the mean DDD values in biosimilars and the originator groups could be considered comparable from a clinical point of view.

\section{Description of outcomes}

Descriptive analysis of the effectiveness and safety outcomes, and mean follow-up time, by clinical setting are reported as online supplementary tables S3-S5. Hypersensitivity reactions were very infrequent in our cohort $(0.2 \%)$ and we took the decision to not calculate single risk estimates for this event. The mean follow-up time for each considered outcome was very similar between biosimilars and all originators in both clinical settings (see online supplementary tables S4 and S5).

\section{Risk estimates in CKD and oncology}

The adjusted HRs for all considered outcomes for the two clinical settings are presented in figure 2A-D.

In the CKD setting, no significant differences on the risk estimates for all-cause mortality, blood transfusion, MACE and blood dyscrasia were found between biosimilars and originators. The composite outcome confirmed these results (biosimilars vs epoetin $\alpha$ originators: adjusted $\mathrm{HR}=1.02,95 \%$ CI 0.78 to 1.33 ; biosimilars vs other originators: adjusted $\mathrm{HR}=1.09,95 \%$ CI 0.85 to 1.41 ).

Similarly, comparable risk estimates can be observed between biosimilars and all originators in the oncology setting when the analysis included the same outcomes. However, in oncology, the comparison between biosimilars and epoetin $\alpha$ originator on the all-cause mortality highlighted a protective effect of biosimilars, although the risk estimate was on the margin of statistical significance (adjusted HR=0.82, 0.70 to 0.97 ). In any case, the composite outcome (which includes all-cause mortality) did not find out any differences between biosimilars and epoetin $\alpha$ originator (adjusted HR 0.91, 0.79 to 1.06 ). For a full interpretation of the results in the oncology setting, we performed a sensitivity analysis in a subgroup of oncology patients enrolled between January 2012 and July 2014 for whom the cause of death was available (see online supplementary table S6) and found that the higher proportion of cause of death was from tumours $(41.9 \%, 561$ out of 1339 patients) in the users of epoetin $\alpha$ originator compared with biosimilars $(35.9 \%$, 113 out of 315 patients), suggestive of potential residual confounding; regression analysis on such a subgroup of 
Table 1 Baseline characteristics of participants enrolled in the study cohort by settings and ESAs (biosimilars, epoetin $\alpha$ originator or other originators)

\begin{tabular}{|c|c|c|c|c|c|c|c|c|c|c|c|c|c|c|c|c|c|c|}
\hline & \multicolumn{9}{|c|}{ Chronic kidney disease setting $(n=8161)$} & \multicolumn{9}{|c|}{ Oncology setting ( $n=5309)$} \\
\hline & \multicolumn{2}{|l|}{$\begin{array}{l}\text { Biosimilars } \\
\text { epoetin } \alpha \\
(\mathrm{N}=154)\end{array}$} & \multicolumn{2}{|c|}{$\begin{array}{l}\text { Originator } \\
\text { epoetin } \alpha \\
(\mathrm{N}=1614)\end{array}$} & \multicolumn{2}{|l|}{$\begin{array}{l}\text { Other } \\
\text { originators } \\
(\mathrm{N}=6393)\end{array}$} & \multirow[b]{2}{*}{$\begin{array}{l}\text { Total } \\
\text { (N=8161) }\end{array}$} & \multirow{2}{*}{$\begin{array}{l}\text { p Value } \\
\text { biosimilars } \\
\text { vs epoetin } \alpha \\
\text { originator }\end{array}$} & \multirow{2}{*}{$\begin{array}{l}\text { p Value } \\
\text { biosimilars } \\
\text { vs other } \\
\text { originators }\end{array}$} & \multicolumn{2}{|l|}{$\begin{array}{l}\text { Biosimilars } \\
\text { epoetin } \alpha \\
(\mathrm{N}=453)\end{array}$} & \multicolumn{2}{|l|}{$\begin{array}{l}\text { Originator } \\
\text { epoetin } \alpha \\
(\mathrm{N}=1617)\end{array}$} & \multicolumn{2}{|l|}{$\begin{array}{l}\text { Other } \\
\text { originators } \\
(\mathrm{N}=3239)\end{array}$} & \multirow{2}{*}{$\begin{array}{l}\text { Total } \\
(\mathrm{N}=5309)\end{array}$} & \multirow{2}{*}{$\begin{array}{l}\text { p Value } \\
\text { biosimilars } \\
\text { vs epoetin } \alpha \\
\text { originator }\end{array}$} & \multirow{2}{*}{$\begin{array}{l}\text { p Value } \\
\text { biosimilar } \\
\text { vs other } \\
\text { originator }\end{array}$} \\
\hline & $\mathbf{N}$ & $\begin{array}{l}\text { Per } \\
\text { cent }\end{array}$ & $\mathrm{N}$ & $\begin{array}{l}\text { Per } \\
\text { cent }\end{array}$ & $\mathrm{N}$ & $\begin{array}{l}\text { Per } \\
\text { cent }\end{array}$ & & & & $\mathrm{N}$ & $\begin{array}{l}\text { Per } \\
\text { cent }\end{array}$ & $\mathrm{N}$ & $\begin{array}{l}\text { Per } \\
\text { cent }\end{array}$ & $\mathrm{N}$ & $\begin{array}{l}\text { Per } \\
\text { cent }\end{array}$ & & & \\
\hline Gender & & & & & & & & 0.9722 & 0.7728 & & & & & & & & & \\
\hline Male & 84 & 54.5 & 878 & 54.4 & 3412 & 53.4 & 4374 & & & 233 & 51.4 & 810 & 50.1 & 1409 & 43.5 & 2452 & 0.6136 & 0.0015 \\
\hline Female & 70 & 45.5 & 736 & 45.6 & 2981 & 46.6 & 3787 & & & 220 & 48.6 & 807 & 49.9 & 1830 & 56.5 & 2857 & & \\
\hline Age (years) & & & & & & & & 0.2059 & 0.1924 & & & & & & & & & \\
\hline$<45$ & 2 & 1.3 & 42 & 2.6 & 162 & 2.5 & 206 & & & 20 & 4.4 & 94 & 5.8 & 169 & 5.2 & 283 & 0.1806 & 0.0931 \\
\hline $45-64$ & 9 & 5.8 & 150 & 9.3 & 631 & 9.9 & 790 & & & 126 & 27.8 & 486 & 30.1 & 1012 & 31.2 & 1624 & & \\
\hline $64-84$ & 54 & 35.1 & 469 & 29.1 & 1913 & 29.9 & 2436 & & & 226 & 49.9 & 804 & 49.7 & 1608 & 49.6 & 2638 & & \\
\hline$>84$ & 89 & 57.8 & 953 & 59.0 & 3687 & 57.7 & 4729 & & & 81 & 17.9 & 232 & 14.3 & 450 & 13.9 & 763 & & \\
\hline Mean (SD) & $79.2(10.2)$ & & $78.6(13.6)$ & & 78.5 (12.8) & & & 0.6179 & 0.5868 & $68.5(11.9)$ & & $67.1(12.6)$ & & $67.0(12.5)$ & & & 0.0210 & 0.0140 \\
\hline $\begin{array}{l}\text { Baseline } \mathrm{Hb} \text { levels } \\
(\mathrm{g} / \mathrm{dL})\end{array}$ & & & & & & & & 0.0168 & 0.3731 & & & & & & & & 0.6748 & 0.1222 \\
\hline$<8$ & 10 & 6.5 & 114 & 7.1 & 279 & 4.4 & 403 & & & 29 & 6.4 & 118 & 7.3 & 165 & 5.1 & 312 & & \\
\hline $8-10$ & 92 & 59.7 & 1105 & 68.5 & 3848 & 60.2 & 5045 & & & 409 & 90.3 & 1460 & 90.3 & 3000 & 92.6 & 4869 & & \\
\hline $10-11$ & 50 & 32.5 & 349 & 21.6 & 2069 & 32.4 & 2468 & & & 12 & 2.6 & 32 & 2.0 & 68 & 2.1 & 112 & & \\
\hline$\geq 11$ & 2 & 1.3 & 46 & 2.9 & 197 & 3.1 & 245 & & & 3 & 0.7 & 7 & 0.4 & 6 & 0.2 & 16 & & \\
\hline Mean (SD) & $9.3(1.3)$ & & $9.2(1.1)$ & & $9.5(1.1)$ & & & 0.1043 & 0.0871 & $9.0(0.8)$ & & $8.9(0.9)$ & & $9.0(0.7)$ & & & 0.2905 & 0.9440 \\
\hline \multicolumn{19}{|l|}{ Other ETP active } \\
\hline $\begin{array}{l}\text { Special nutrition } \\
\text { programme }\end{array}$ & 9 & 5.8 & 72 & 4.5 & 552 & 8.6 & 633 & 0.4328 & 0.2215 & 1 & 0.2 & 2 & 0.1 & 3 & 0.1 & 6 & 0.6312 & 0.4375 \\
\hline \multicolumn{19}{|l|}{$\begin{array}{l}\text { Comorbidities in } \\
\text { the previous }\end{array}$} \\
\hline Diabetes & 69 & 44.8 & 740 & 45.8 & 2756 & 43.1 & 3565 & 0.8038 & 0.6746 & 101 & 22.3 & 373 & 23.1 & 702 & 21.7 & 1176 & 0.7298 & 0.7636 \\
\hline Hypertension & 50 & 32.5 & 680 & 42.1 & 2227 & 34.8 & 2957 & 0.0200 & 0.5422 & 82 & 18.1 & 259 & 16.0 & 557 & 17.2 & 898 & 0.2905 & 0.6335 \\
\hline Heart diseases & 75 & 48.7 & 695 & 43.1 & 2098 & 32.8 & 2868 & 0.1774 & $<0.001$ & 33 & 7.3 & 142 & 8.8 & 242 & 7.5 & 417 & 0.3114 & 0.8873 \\
\hline Arrhythmia & 39 & 25.3 & 380 & 23.5 & 1122 & 17.6 & 1541 & 0.6195 & 0.0126 & 20 & 4.4 & 79 & 4.9 & 129 & 4.0 & 228 & 0.6783 & 0.6614 \\
\hline Heart failure & 55 & 35.7 & 477 & 29.6 & 1399 & 21.9 & 1931 & 0.1113 & $<0.001$ & 7 & 1.5 & 33 & 2.0 & 61 & 1.9 & 101 & 0.4983 & 0.6162 \\
\hline $\begin{array}{l}\text { Cerebrovascular } \\
\text { disease }\end{array}$ & 21 & 13.6 & 295 & 18.3 & 794 & 12.4 & 1110 & 0.1509 & 0.6514 & 14 & 3.1 & 68 & 4.2 & 129 & 4.0 & 211 & 0.2823 & 0.3566 \\
\hline $\begin{array}{l}\text { Arterial and } \\
\text { venous } \\
\text { thrombosis }\end{array}$ & 1 & 0.6 & 47 & 2.9 & 129 & 2.0 & 177 & 0.0988 & 0.2290 & 8 & 1.8 & 42 & 2.6 & 87 & 2.7 & 137 & 0.3084 & 0.2467 \\
\hline $\begin{array}{l}\text { Number of } \\
\text { hospitalisations in } \\
\text { the previous } \\
2 \text { years }\end{array}$ & & & & & & & & 0.0215 & 0.7635 & & & & & & & & 0.2978 & 0.8025 \\
\hline 0 & 42 & 27.3 & 285 & 17.7 & 1950 & 30.5 & 2277 & & & 102 & 22.5 & 340 & 21.0 & 686 & 21.2 & 1128 & & \\
\hline 1 & 43 & 27.9 & 459 & 28.4 & 1807 & 28.3 & 2309 & & & 134 & 29.6 & 454 & 28.1 & 955 & 29.5 & 1543 & & \\
\hline $2-3$ & 48 & 31.2 & 568 & 35.2 & 1774 & 27.7 & 2390 & & & 144 & 31.8 & 498 & 30.8 & 1021 & 31.5 & 1663 & & \\
\hline$>3$ & 21 & 13.6 & 302 & 18.7 & 862 & 13.5 & 1185 & & & 73 & 16.1 & 325 & 20.1 & 577 & 17.8 & 975 & & \\
\hline \multicolumn{19}{|c|}{ ETP duration (months) } \\
\hline Mean (SD) & $2.7(1.6)$ & & $3.5(2.3)$ & & $3.3(1.6)$ & & & $<0.0001$ & $<0.0001$ & $3.3(1.9)$ & & $3.4(1.7)$ & & $3.8(1.6)$ & & & 0.1738 & $<0.001$ \\
\hline \multicolumn{19}{|c|}{ Number of ESA packages dispensed } \\
\hline Mean (SD) & $7.8(3.5)$ & & $9.0(4.1)$ & & $4.2(1.9)$ & & & 0.0004 & $<0.0001$ & $4.4(1.1)$ & & $4.9(2.7)$ & & $4.1(1.3)$ & & & $<0.001$ & $<0.001$ \\
\hline DDD & & & & & & & & & & & & & & & & & & \\
\hline Mean (SD) & $158.9(192.2)$ & & $200.4(240.5)$ & & $122.2(131.1)$ & & & 0.0378 & 0.0007 & $475.3(33.6)$ & & $569.7(314.1)$ & & $531.0(267.2)$ & & & $<0.001$ & $<0.001$ \\
\hline
\end{tabular}



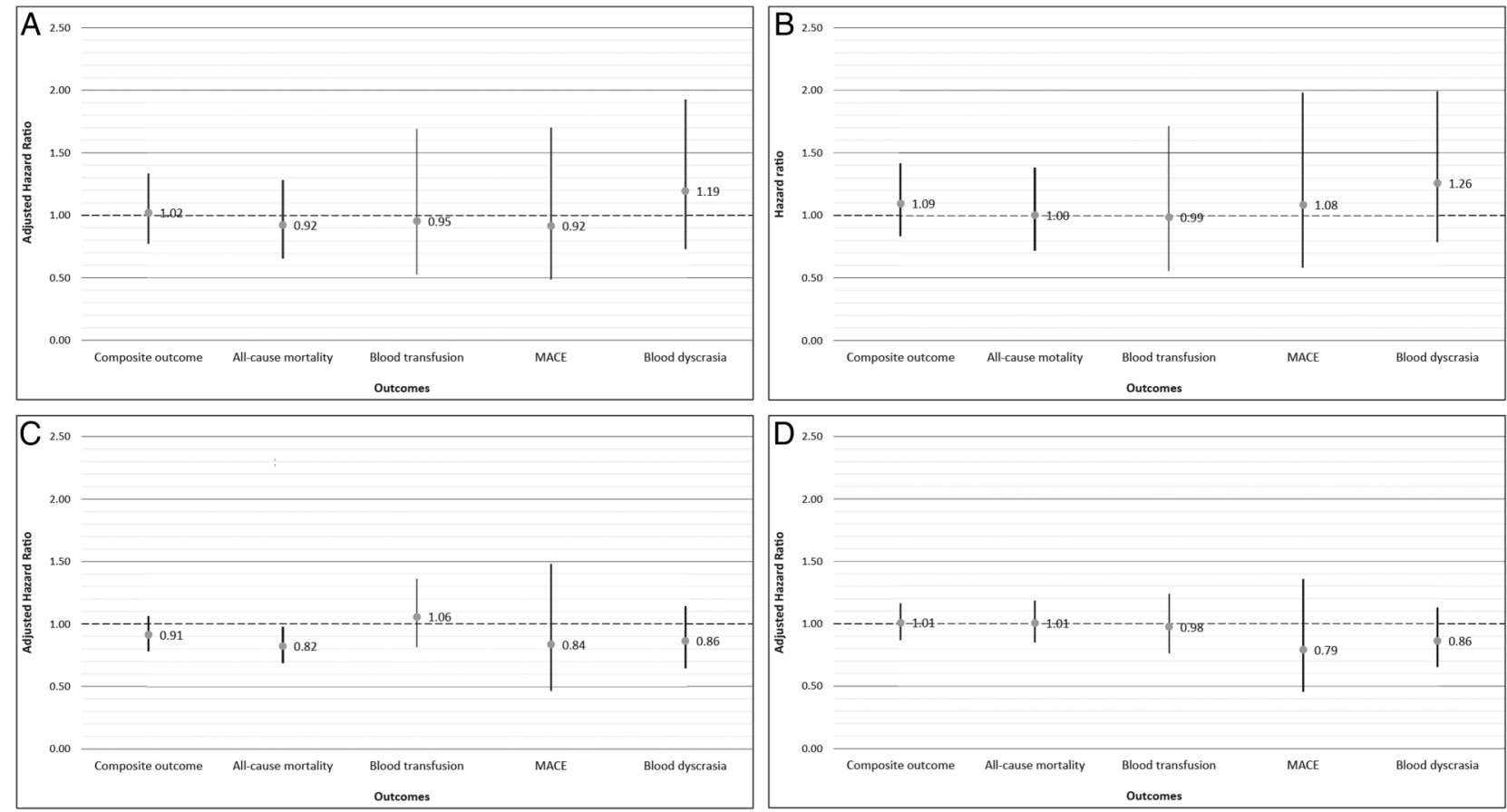

Figure 2 (A-D) HRs for the effectiveness and safety outcomes by settings. Green dots were the value of the HR estimate and the line represented the lower and upper values of the Cls. CKD, chronic kidney disease; MACE, major cardiovascular events.

patients confirmed previous findings on the overall mortality (see online supplementary table S7).

Results of the multivariate analysis in the CKD and oncology settings showing crude and adjusted HRs and related CIs are reported in online supplementary table S8; details on the statistical model on all effectiveness and safety outcomes are given for the CKD and oncology settings, respectively (see online supplementary tables S9A,B and S10A,B). Apropos of the CKD setting, we noted that lower age, higher baseline $\mathrm{Hb}$ levels and lower hospitalisation favoured biosimilars on the composite outcome. The role of comorbidities as predictors of outcomes in patients taking biosimilars is instead controversial.

In the oncology setting, female gender, higher baseline $\mathrm{Hb}$ levels and lower hospitalisation also favoured biosimilars on the composite outcome. Patients taking biosimilars for anticancer chemotherapy induced anaemia with underlying cardiovascular diseases were at higher risk of negative effectiveness and safety outcomes if compared with all the originators.

After genetic matching, we included 462 patients in the CKD setting and 1359 patients in the oncology setting; the biosimilar users and originator users were well balanced with respect to baseline characteristics (see online supplementary table S11). Repeating the analysis using the genetic matched cohorts did not alter the results for the considered outcomes (table 2).

The lower mortality risk with biosimilars when compared with epoetin $\alpha$ originator in the oncology setting remained unaltered in the genetic matched analysis (genetic matched HR 0.76, 0.62 to 0.93 ).
Survival curves and cumulative probabilities of receiving a blood transfusion by ESAs exposure status confirmed the time relationships for such events and the exposure to biosimilars or epoetin $\alpha$ originator or other biosimilars in both clinical settings (see online supplementary figure S1A-D). In the survival analysis, the lower probability of survival with epoetin $\alpha$ originator continued to be present in the oncology setting.

\section{Determinants of prescription for biosimilars (CKD and oncology)}

The predictive model largely confirmed that the selected variables related to patients' characteristics did not affect the probability of receiving an ETP for biosimilars or originators in the CKD and oncology settings (see online supplementary table S12).

In the CKD setting, the higher the number of previous hospitalisations, the smaller the probability of receiving a biosimilar: patients without previous hospitalisation had a risk more than threefold higher of receiving a biosimilar than the epoetin $\alpha$ originator (adjusted $\mathrm{OR}=3.12,95 \%$ CI 1.69 to 5.75 ). The patterns of risk estimates for the prescription of a biosimilar were comparable when biosimilars were resembled with the two groups of originators (ie, epoetin $\alpha$ originator and other originators). The presence of comorbidities was a factor found to be associated with the prescription of biosimilars. A positive association with biosimilar prescription was found in patients with underlying severe cardiovascular diseases such as heart failure (adjusted $\mathrm{OR}=1.82$, $95 \%$ CI 1.22 to 2.71 when the comparator is the epoetin $\alpha$ originator) and heart diseases (adjusted $\mathrm{OR}=2.21$, 


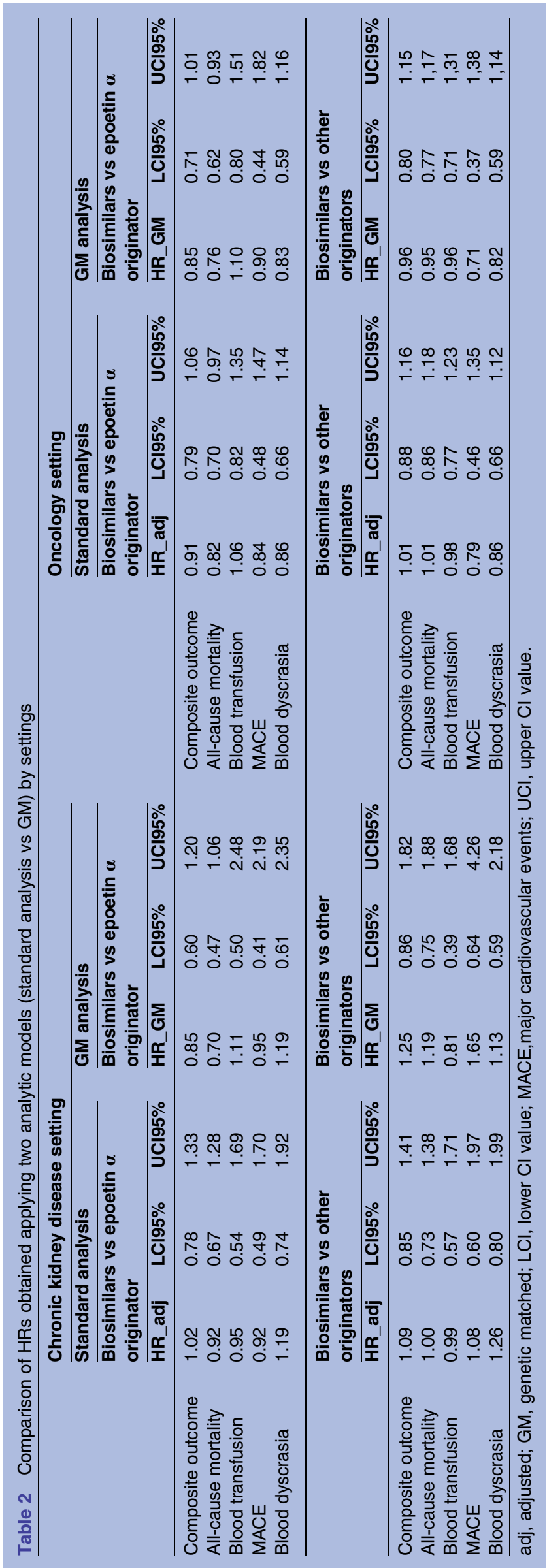

95\% CI 1.49 to 3.28 when the comparators are other originators).

Among the variables selected as determinants for use in the oncology setting, gender (ie, being female) was the only factor negatively associated with a prescription of biosimilars when compared with other originators (adjusted $\mathrm{OR}=0.73$, 95\% CI 0.60 to 0.90 ).

\section{DISCUSSION}

To the best of our knowledge, this is the first study comparing the effectiveness and safety of ESA biosimilars with all the originators in incident ESA users and on hard clinical outcomes. This is the largest sample of patients from the real-world practice and covers the principal therapeutic indications of ESAs including both CKD and the oncology settings.

\section{Statement of principal findings}

In both settings, our findings are suggestive of no difference between biosimilars and originators on relevant effectiveness and safety outcomes measured during the follow-up period.

\section{Strengths and weaknesses of the study}

Many potential confounders identified through multiple database linkage were considered allowing high completeness of data. Moreover, the data source for population involved in the study was set up for the clinical purpose of increasing the appropriate ESAs use and as part of reimbursement procedures by the NHS. This permits to ensure a very low misclassification of diagnosis and incident users (information certified by a specialist for the activation of an ETP). The ETPR also includes clinical data on the correct treatment indication in oncology and CKD according to the guidelines which ensure a selected cohort of patients for which ESAs use is deemed appropriate.

Several prespecified subgroup analyses were also performed on the considered outcomes in both settings to inform on the heterogeneity of results. Finally, we also investigated the time relationships between ESAs exposure and specific outcomes such as mortality and blood transfusion and found no different distribution over time for these events.

We were not able to control our estimates for some confounding factors such as iron supplementation, smoking status, body mass index, socioeconomic status as well as ESAs dose/posology which may affect the aetiology of the selected outcomes and may be associated with the decision to start the therapy with such drugs. Moreover, relevant information for the oncology setting (eg, tumour type, stage, chemotherapy) was not available and this should be considered as a study limitation.

For instance, in the CKD setting we found that patients on biosimilars were overall less severe than those staring an originator, since they had a higher $\mathrm{Hb}$ level at baseline and a lower prevalence of previous 
cardiovascular comorbidities. This could be explained by the scepticism of clinicians towards the use of biosimilars (supposed as less effective) which may channel severe patients to the originators (supposed as more effective).

As per protocol, we applied a fixed follow-up period to all ESA users for the outcome evaluation. On the basis of the study period and the data availability, we were able to guarantee up to 6 months of follow-up to all patients enrolled in the cohort. Although this may appear as a short follow-up, it turned to be sufficient to observe a mortality rate of $24.6 \%$ in the patient with CKD (2011 out of 8161; a mean follow-up of 4.2 months) and $40.2 \%$ in the oncology setting (2132 out of 5309; a mean follow-up of 3.8 months).

As with other observational studies based on routinely collected data exposure, misclassification is possible since we cannot assure that all ESA packages prescribed to (and received by) patients were then administered. However, such misclassifications are expected to be nondifferential between the groups.

\section{Comparison with other studies}

The clinical evidence in the CKD setting is more consolidated and comes from RCTs, and has been recently appraised by a network meta-analysis. ${ }^{15}$ Overall, 12103 adult patients with CKD from 40 RCTs were analysed for efficacy and safety outcomes, although only 25 studies (enrolling 6678 participants) were head-to-head studies of ESAs. It was possible to compare ESAs to each other only on selected outcomes such as blood transfusion, allcause mortality and MACE. No statistical differences between ESAs (originators vs biosimilars) emerged on blood transfusion, although the uncertainty is high given the wide CIs of the risk estimates. Similar conclusions were provided for the association between different ESAs and all-cause mortality or MACE. More specifically, meta-analysis of three studies with epoetin $\alpha$ originator versus biosimilars enrolling 1823 participants showed no difference on blood transfusion (OR 0.72, 0.42 to 1.22). ${ }^{24-26}$ Similar results were obtained from the meta-analysis of seven studies with a sample of 2220 patients comparing epoetin $\alpha$ originator with biosimilar on all-cause mortality (OR 1.04, 0.53 to 2.01$) .^{2425} 27-31$ Risk estimates on MACE come from only one study (462 patients) comparing epoetin $\alpha$ originator versus biosimilars and was inconclusive (OR $0.49,0.17$ to 1.47 ). ${ }^{24}$

In oncology, the evidence from comparative effectiveness of ESAs used for the management of chemotherapy-induced anaemia is generally poor. Only one observational study involving 429 patients in two centres in Germany and Spain aiming at comparing a biosimilar with darbepoetin $\alpha$ was published in 2014. ${ }^{17}$ This study highlighted no difference between a biosimilar or darbepoetin $\alpha$ in terms of mean increase in $\mathrm{Hb}$ levels, while incidence of blood transfusion was statistically significantly higher in the darbepoetin $\alpha$ group (14.3\% vs $8 \%$, respectively). However, this study was too small and the duration of ESA treatment was limited $(<5$ weeks $)$.

Our study was conducted on the largest patient population enrolled in real clinical practice consisting of 8161 patients with CKD and 5309 oncology patients who started the treatment with ESA. It covers a broader series of relevant effectiveness and safety outcomes, measured during a 6-month follow-up period. We performed direct comparisons between biosimilars and all originators for all the aforementioned outcomes and also added the comparison between biosimilars and other originators (different from epoetin $\alpha$ ). In this context, we found no difference between biosimilars compared with all originators (including those still covered by a patent) in terms of effectiveness and safety outcomes.

Applying different statistical approaches and evaluating several clinical outcomes, the risk estimates obtained in our study are consistent across all the comparisons and settings. Specifically, when considering the composite outcome, where maximum power can be achieved, we obtained a HR point estimate ranging from 0.91 and 1.09 with CIs including 1 (not statistically significant). In any case, the lower CI of the composite outcome was 0.78 , while the upper CI was 1.41 .

It should be underlined that the absence of statistical significance does not automatically mean absence of a meaningful clinical difference. However, in the CKD setting, observational real-world data provided similar risk estimates than those obtained from RCT data included in the network meta-analysis.

No comparative data are available in the scientific literature evaluating the risk of mortality between ESA biosimilars and originators. We found an increased risk on mortality with epoetin $\alpha$ originator when compared with biosimilars, which needs to be interpreted with caution and should be further confirmed by other research. Moreover, the subgroup analysis conducted showed that patients with cancer on epoetin $\alpha$ originator had a higher incidence of death from cancer, highlighting a potential channelling for prescription of biosimilar to less severe patients which could contribute to the residual confounding. Furthermore, several factors such as the tumour type and stage, time from diagnosis or different treatments (eg, dosages, cycles, drug classes, other therapies) which might also contribute to residual confounding, should be considered in future research because of their impact on severity of cancers and ultimately affect the mortality. For the sake of information, it should be pointed out that a meta-analysis of RCT conducted by Bohlius et $a l^{22}$ in 2009 showed that ESAs in patients with cancer increased mortality. However, this meta-analysis was done prior to the biosimilar era and different ESAs (epoetin and darbepoetin) were considered together. This meta-analysis did not investigate risk difference on mortality by different ESAs.

We also found a controversial role for comorbidities in the CKD setting, since patients on biosimilars present a higher incidence of previous AMI, heart failure and 
arrhythmias (although less hypertensive) when compared with those on originators. However, these findings are in line with another drug usage study conducted in Germany which highlights similar findings. ${ }^{33}$

This latter study also adds an important piece of information in a severe CKD subpopulation (ie, patients in haemodialysis) demonstrating that patients receiving ESAs for six accounting quarters had comparable DDD when taking biosimilar or originator ESAs. ${ }^{33}$

\section{Meaning of the study}

Our study was conducted region wide in the Lazio Region, which is the second largest Italian region by resident population; therefore, study results should be considered generalisable to the whole Italian population.

The present real-life data confirm that ESA biosimilars are as effective and safe as the ESA originators, thus contributing to overcome barriers still raised for their prescription. Our findings can be of paramount significance for policymakers who are facing with sustainability of the NHSs. In fact, promoting the take-up of ESA biosimilars easily translates into millions of euro savings which may be allocated to innovative (and often more costly) medicines. In addition, study findings might be evaluated directly by expert groups of clinicians (also in collaboration with patients) in order to produce new clinical guidance or update existing ones.

Our study also provides reassurance on the current approval pathway for biosimilars, especially regarding the 'data extrapolation' process, which was specifically applied for ESA biosimilars for the indication in anticancer chemotherapy-induced anaemia. Indeed, we highlighted no difference on relevant outcomes between ESA biosimilars and ESA originators in the oncology setting. It should also be pointed out, however, that extrapolation is a rational consequence of the biosimilar concept always adopted. The scientific literature shows that extrapolation is not new, since it has already been used for many years with changes in the manufacturing process for originator biological and biotechnological products, where often more than minor changes were observed after authorisation between different lots. ${ }^{34-36}$

\section{Unanswered questions and future research}

We did not address the effect of switching strategies between different ESA products on clinical outcomes nor the influence of the different hospitals or specialists on the prescription of biosimilar or originators.

Moreover, the comparative effectiveness and safety of all ESA products in highly severe nephrology settings, for example, dialysed or transplanted patients, remains to be investigated.

The oncology setting merits further research, taking into account tumour types, tumour stage and anticancer chemotherapy administered.

Finally, the replication of these results in both settings, also considering patient preferences or using patientreported outcomes linked with the quality of life, will add an important piece of information and increase the consistency of our findings.

\section{CONCLUSIONS}

This study suggests a comparable benefit/risk profile of biosimilars of epoetin $\alpha$ when compared with all the ESA originators in real-life practice and may contribute to settling future drug policy for the health services. Forthcoming research and related meta-analysis could further define specific risks in the oncology setting.

Acknowledgements The authors wish to thank Ursula Kirchmayer of the Department of Epidemiology of Lazio Regional Health Service for comments and suggestions on the final version of the manuscript.

Contributors FT and AA conceived the study. FT, VB, AA, DF, LA and MD designed the study. FT, VB, AA, DF and FM analysed the data. FT and AA wrote the manuscript. FT, VB, AA, DF, LA and FM contributed to the discussion and reviewed the manuscript. All authors saw, commented on and approved the final version of the paper. AA and MD are the guarantors.

Funding Only public employees of the regional health authorities were involved in conceiving, planning and conducting the study.

Competing interests None declared.

Provenance and peer review Not commissioned; externally peer reviewed.

Data sharing statement The authors are willing to collaborate in answering further research questions and to participate in systematic reviews or meta-analyses.

Open Access This is an Open Access article distributed in accordance with the Creative Commons Attribution Non Commercial (CC BY-NC 4.0) license, which permits others to distribute, remix, adapt, build upon this work noncommercially, and license their derivative works on different terms, provided the original work is properly cited and the use is non-commercial. See: http:// creativecommons.org/licenses/by-nc/4.0/

\section{REFERENCES}

1. Associazione Italiana di Oncologia Medica. Linee Guida Gestione della tossicità ematopoietica in oncologia. Milan, 2015:50p. http:// www.aiom.it/professionisti/documenti-scientifici/linee-guida/ tossicit-ematopoietica/1,710,1

2. Kidney Disease: Improving Global Outcomes (KDIGO) Anemia Work Group. KDIGO clinical practice guideline for anemia in chronic kidney disease. Kidney Int Suppl 2012;2:279-335.

3. Sistema Nazionale Linee Guida -Istituto Superiore di Sanità, Società Italiana di Nefrologia, Ministero della Salute. Linea Guida "Identificazione, prevenzione e gestione della Malattia Renale Cronica nell'adulto". Rome, 2012:136p. http://www.snlg-iss.it/lgn_ malattia_renale

4. Aapro MS, Link H. September 2007 update on EORTC guidelines and anemia management with erythropoiesis-stimulating agents. Oncologist 2008;13(Suppl 3):S33-6.

5. Rizzo JD, Brouwers M, Hurley P, et al. American Society of Clinical Oncology, American Society of Hematology. American Society of Clinical Oncology/American Society of Hematology clinical practice guideline update on the use of epoetin and darbepoetin in adult patients with cancer. J Clin Oncol 2010;28:4996-5010.

6. National Comprehensive Cancer Network (NCCN). NCCN guidelines. Cancer- and chemotherapy-induced anemia (version 2.2016). USA, 2015:50p. Available from: http://www.nccn.org/ professionals/physician_gls/f_guidelines.asp

7. Greer JW, Milam RA, Eggers PW. Trends in use, cost, and outcomes of human recombinant erythropoietin, 1989-98. Health Care Financ Rev 1999;20:55-62.

8. European Survey on Anaemia Management (ESAM). Nephrol Dial Transplant 2000;15(Suppl 4):S1-76.

9. Open database. European public assessment reports. London: The European Medicines Agency. (cited 2016 January 5). http://www. ema.europa.eu/ema/index.jsp?curl=pages/medicines/landing/epar search.jsp\&mid=WCOb01ac058001d124 
10. European Medicines Agency. Committee for Medicinal Products for Human Use (CHMP). Guideline on similar biological medicinal products containing biotechnology-derived proteins as active substance: non-clinical and clinical issues (EMEA/CHMP/BMWP/42832/2005 Rev1). London, 2014:13p. http://www.ema.europa.eu/docs/en_GB/ document_library/Scientific_guideline/2015/01/WC500180219.pdf

11. Dylst $P$, Vulto A, Simoens S. Barriers to the uptake of biosimilars and possible solutions: a Belgian case study. Pharmacoeconomics 2014;32:681-91.

12. Rompas S, Goss T, Amanuel S, et al. Demonstrating value for biosimilars: a conceptual framework. Am Health Drug Benefits 2015;8:129-39.

13. Italian Medicines Agency. The Medicines Utilisation Monitoring Centre (OsMed). National Report on Medicines use in Italy. Year 2014. Rome, 2015:522. http://www.agenziafarmaco.gov.it/it/content/ rapporti-osmed-luso-dei-farmaci-italia

14. Ingrasciotta $Y$, Giorgianni F, Bolcato J, et al. How much are biosimilars used in clinical practice? A retrospective Italian population-based study of erythropoiesis-stimulating agents in the years 2009-2013. BioDrugs 2015;29:275-84

15. Palmer SC, Saglimbene V, Mavridis D, et al.

Erythropoiesis-stimulating agents for anaemia in adults with chronic kidney disease: a network meta-analysis. Cochrane Database Syst Rev 2014;(12):CD010590.

16. Barosi G, Bosi A, Abbracchio MP, et al. Key concepts and critical issues on epoetin and filgrastim biosimilars. A position paper from the Italian Society of Hematology, Italian Society of Experimental Hematology, and Italian Group for Bone Marrow Transplantation. Haematologica 2011;96:937-42.

17. Rodriguez Garzotto A, Cortijo Casacajares S, Pernaut C, et al. Erythropoiesis-stimulating agents for the treatment of chemotherapy-induced anemia: comparisons from real-world clinica experience. J Blood Med 2014;5:43-8.

18. Michallet M, Luporsi E, Soubeyran $\mathrm{P}$, et al. BiOsimilaRs in the management of anaemia secondary to chemotherapy in HaEmatology and Oncology: results of the ORHEO observational study. BMC Cancer 2014;14:503.

19. Michallet M, Losem C. Biosimilar epoetin zeta in oncology and haematology: development and experience following 6 years of use. Acta Haematol 2016;135:44-52.

20. Ebbers HC, Muenzberg M, Schellekens $\mathrm{H}$. The safety of switching between therapeutic proteins. Expert Opin Biol Ther 2012;12:1473-85.

21. Ebbers HC, Mantel-Teeuwisse AK, Moors EH, et al. Today's challenges in pharmacovigilance: what can we learn from epoetins? Drug Saf 2011;34:273-87.

22. Dipartimento di Epidemiologia della Regione Lazio. Lo stato di salute della popolazione del Lazio 2010-2012. Roma, 2015. http:// 95.110.213.190/statosal_10-12/note_metod_pat.php?menu=s52
23. Diamond A, Jasjeet SS. Genetic matching for estimating causal effects: a general multivariate matching method for achieving balance in observational studies. Rev Econ Stat 2013;95:932-45.

24. Krivoshiev S, Wizemann V, Czekalski S, et al. Therapeutic equivalence of epoetin zeta and alfa, administered subcutaneously, for maintenance treatment of renal anemia. Adv Ther 2010;27:105-17.

25. Krivoshiev S, Todorov VV, Manitius J, et al., Epoetin Zeta Study Group. Comparison of the therapeutic effects of epoetin zeta and epoetin alpha in the correction of renal anaemia. Curr Med Res Opin 2008;24:1407-15

26. Martin KJ, Epoetin Delta 3001 Study Group. Epoetin delta in the management of renal anaemia: results of a 6-month study. Nephrol Dial Transplant 2007;22:3052-4

27. Milutinovic S, Plavljanić E, Trkulja V. Comparison of two epoetin brands in anemic hemodialysis patients: results of two efficacy trials and a single-dose pharmacokinetic study. Fundam Clin Pharmacol 2006;20:493-502.

28. Spinowitz BS, Pratt RD, Epoetin Delta 2002 Study Group. Epoetin delta is effective for the management of anaemia associated with chronic kidney disease. Curr Med Res Opin 2006;22:2507-13.

29. Goh BL, Ong LM, Sivanandam S, et al., Biogeneric EPO Study Group. Randomized trial on the therapeutic equivalence between Eprex and GerEPO in patients on haemodialysis. Nephrology (Carlton) 2007;12:431-6.

30. Haag-Weber M, Vetter A, Thyroff-Friesinger U, et al. NJ-Study Group. Therapeutic equivalence, long-term efficacy and safety of HX575 in the treatment of anemia in chronic renal failure patients receiving hemodialysis. Clin Nephrol 2009;72:380-90.

31. Haag-Weber M, Eckardt KU, Hörl WH, et al. Safety, immunogenicity and efficacy of subcutaneous biosimilar epoetin- $\alpha$ (HX575) in non-dialysis patients with renal anemia: a multi-center, randomized, double-blind study. Clin Nephrol 2012;77:8-17.

32. Bohlius J, Schmidlin $\mathrm{K}$, Brillant $\mathrm{C}$, et al. Recombinant human erythropoiesis-stimulating agents and mortality in patients with cancer: a meta-analysis of randomised trials. Lancet 2009;373:1532-42.

33. Hörbrand F, Bramlage P, Fischaleck J, et al. A population-based study comparing biosimilar versus originator erythropoiesisstimulating agent consumption in 6,117 patients with renal anaemia. Eur J Clin Pharmacol 2013;69:929-36.

34. Weise M, Kurki P, Wolff-Holz E, et al. Biosimilars: the science of extrapolation. Blood 2014;124:3191-6.

35. Schiestl M, Stangler T, Torella C, et al. Acceptable changes in quality attributes of glycosylated biopharmaceuticals. Nat Biotechnol 2011;29:310-12.

36. Schneider CK. Biosimilars in rheumatology: the wind of change. Ann Rheum Dis 2013;72:315-18. 